\title{
Conceptualización docente acerca de las características, necesidades educativas especiales y posibles respuestas pedagógicas para los educandos con superdotación en Costa Rica
}

\author{
Krissia Morales Chacón \\ Universidad Estatal a Distancia, 474 - 2050 San Pedro Montes de Oca, San José-Costa Rica; kmorales@uned.ac.cr \\ Recibido 3-VI-2009 Corregido 1-IV-2009 Aceptado 7-V-2009
}

\begin{abstract}
Opinion of teachers about the characteristics, special education needs and care of gifted students in Costa Rica. Few countries have the staff and facilities required for gifted students. I surveyed a sample of 279 teachers (preschool and primary) in the provinces of San José, Alajuela and Limón, Costa Rica about their knowledge of the subject, characteristics of gifted learners and their ability to properly educate them. Their general view of the subject tends to coincide with that of experts but they also believe in several myths. Costa Rican teachers are not trained to deal properly with gifted students but believe that gifted students should be integrated into the regular educational system.
\end{abstract}

\section{KEY WORDS}

Giftedness, talent, teachers, special education needs, research, grouping, acceleration and curricular adaptation, curricular enrichment, integration

Los cambios hacia una educación más personal y menos masificada, han dado como resultado una mayor conciencia de los educandos como seres individuales y con necesidades particulares, surgiendo así, principios y políticas educativas tendientes a la atención de aquellos estudiantes que por tener necesidades educativas especiales, requieren métodos, técnicas y estrategias de enseñanza-aprendizaje innovadoras y procesos de mediación docente creativos para lograrlo. Estos cambios paradigmáticos han derivado en una nueva legislación y políticas educativas que se concretan en procesos de reestructuración educativa y curricular, y que además, manifiestan requerimientos impostergables en la formación profesional y la capacitación del profesorado, para proveer respuestas educativas apropiadas a las poblaciones escolares con necesidades educativas especiales (Alonso y Benito 2004).

En Costa Rica como en muchas otras naciones, los esfuerzos no han sido equitativos para con aquellos que por sus altas capacidades o alta dotación necesitan apoyos pedagógicos individualizados, y que también son parte de la diversidad escolar. Se ha pasado inadvertida su situación en el ámbito educativo formal, provocando en muchos casos, problemas asociados a esta condición, sobre los cuales se les ha etiquetado negativamente, propiciando actitudes conformistas y apatía o simplemente la adaptación forzada a un sistema desmotivador que mutila su verdadero potencial; por lo tanto, es indudable que debemos reaccionar y actuar para que estas condiciones sean modificadas (Morales 2007).

Es recomendable comenzar trabajando con el recurso humano con el que interactúan los niños y las niñas dentro de la comunidad educativa: los docentes. Por ello, esta investigación identifica la condición de formación e información que poseen los docentes del sistema pedagógico regular (el estudio incluyó profesorado de preescolar y enseñanza general básica) respecto a la conceptualización, necesidades educativas y posibles alternativas o respuestas educativas para la atención docente del alumnado con superdotación infantil en Costa Rica. 


\section{METODOLOGÍA}

Los sujetos (docentes) fueron designados como resultado de seleccionar al azar una serie de instituciones educativas (preescolar y primaria) en las provincias de San José, Limón y Alajuela; en cada una de las direcciones regionales cuentan con listas de los centros educativos bajo su jurisdicción, de ahí se seleccionaron nombres de instituciones, tomando en cuenta la cantidad de docentes hasta completar un total de 279. La información fue suministrada por el Departamento de Estadística del Ministerio de Educación Pública, MEP, 2006.

Se distribuyeron 350 instrumentos a los docentes, para corregir el efecto de cuestionarios no debidamente devueltos.

La"entrevista de opinión docente" (Apéndice 2) fue aplicada en forma aleatoria entre profesores(as) de preescolar y primaria de escuelas urbanas en la provincia de San José.

Una vez obtenida la información, se procedió a elaborar un listado con todas las respuestas, eliminando las menos frecuentes hasta obtener los cinco ítems que representaban las respuestas coincidentes de la mayoría. Se incluyeron estos ítems con cinco criterios teóricos tradicionales y otros cinco dados por expertos contemporáneos. Los 15 ítems permiten comprobar si hay coincidencia entre las tres fuentes de información.

El segundo instrumento es un cuestionario de opinión, dirigido a docentes de preescolar y primaria, con 57 ítems de tipo cerrado (selección) y 11 ítems de tipo abierto (desarrollo) (Apéndice 3)

\section{RESULTADOS}

Los docentes consideran las altas calificaciones como un descriptor de la superdotación.

Los niños y niñas con alta dotación son percibidos como "especiales", con altos niveles de conciencia, sensibilidad y capacidad para analizar la realidad del entorno, lo cual les facilita tener mayor perceptibilidad, criterio y capacidad de entendimiento de las situaciones y acciones que les rodean (Cuadro 1).

Los encuestados opinan que son rasgos de superdotación el ser hábil, la sensibilidad ante los problemas sociales y la capacidad de memoria, entre otras características (Cuadro 2).

Según el juicio de los docentes, el ser investigadores o curiosos por naturaleza, la capacidad intelectual y el ser talentosos o sobresaliente son rasgos que definen con mayor precisión a los niños con superdotación (Fig. 1).

Por su parte, los expertos indican como señales de superdotación la creatividad y una capacidad superior al promedio (Fig. 2).

En cuanto a los argumentos teóricos, las características seleccionadas como típicas de los niños superdotados, se encuentran el afán por aprender, la capacidad de memoria y una buena autoestima (Fig. 3).

Aproximadamente la mitad de los docentes tienen un concepto de la superdotación infantil que coincide con los criterios de los expertos.

Los aspectos calificados con grado de "mucho", como la creatividad, sensibilidad ante los problemas sociales,

CUADRO 1

Descriptores utilizados por los docentes para definir a los educandos con superdotación (Conceptualización)

\begin{tabular}{lccccccc}
\hline & $\begin{array}{c}\text { Investigadores } \\
\text { / curiosos por } \\
\text { naturaleza }\end{array}$ & $\begin{array}{c}\text { Capacidad por } \\
\text { encima del } \\
\text { promedio }\end{array}$ & $\begin{array}{c}\text { Calificaciones } \\
\text { altas }\end{array}$ & $\begin{array}{c}\text { Compromiso } \\
\text { con las tareas }\end{array}$ & Autoestima & Creatividad Talentosos (as) \\
\hline Nada & 0,4 & 0,7 & 1,1 & 1,1 & 0,7 & 0,7 & - \\
Poco & 5,0 & 6,1 & 8,2 & 16,8 & 16,8 & 7,9 & 7,5 \\
Bastante & 24,4 & 32,3 & 45,9 & 39,1 & 32,6 & 24,4 & 35,8 \\
Mucho & 68,8 & 56,3 & 34,4 & 35,5 & 41,9 & 63,1 & 50,5 \\
No Responde & 1,4 & 4,7 & 10,4 & 7,5 & 7,9 & 3,9 & 6,1 \\
Total & $\mathbf{2 7 9}$ & $\mathbf{2 7 9}$ & $\mathbf{2 7 9}$ & $\mathbf{2 7 9}$ & $\mathbf{2 7 9}$ & $\mathbf{2 7 9}$ & $\mathbf{2 7 9}$ \\
\hline
\end{tabular}


CUADRO 2

Rasgos de los niños con superdotación, según los entrevistados

\begin{tabular}{lccccccc}
\hline & $\begin{array}{c}\text { Capacidad de } \\
\text { juicio ético } \mathbf{y} \\
\text { sentido de justicia }\end{array}$ & $\begin{array}{c}\text { Hábiles } \\
\text { Nada }\end{array} \quad \begin{array}{c}\text { Sensibilidad ante } \\
\text { los problemas } \\
\text { sociales }\end{array}$ & $\begin{array}{c}\text { Capacidad de } \\
\text { memoria }\end{array}$ & $\begin{array}{c}\text { Capacidad } \\
\text { intelectual }\end{array}$ & $\begin{array}{c}\text { Capacidad de } \\
\text { liderazgo }\end{array}$ & $\begin{array}{c}\text { Afán por } \\
\text { aprender }\end{array}$ \\
\hline Noco & 1,1 & 0,4 & 2,2 & 0,4 & 0,7 & 1,8 & 1,1 \\
Bastante & 17,9 & 8,6 & 29,7 & 7,9 & 3,9 & 20,4 & 2,9 \\
Mucho & 41,9 & 39,4 & 36,2 & 30,5 & 27,2 & 38,7 & 24,7 \\
No Responde & 29.4 & 42,3 & 21,1 & 55,2 & 60,2 & 29,0 & 65,9 \\
Total & 9,7 & 9,3 & 10,8 & 6,1 & 7,9 & 10,0 & 5,4 \\
\hline
\end{tabular}

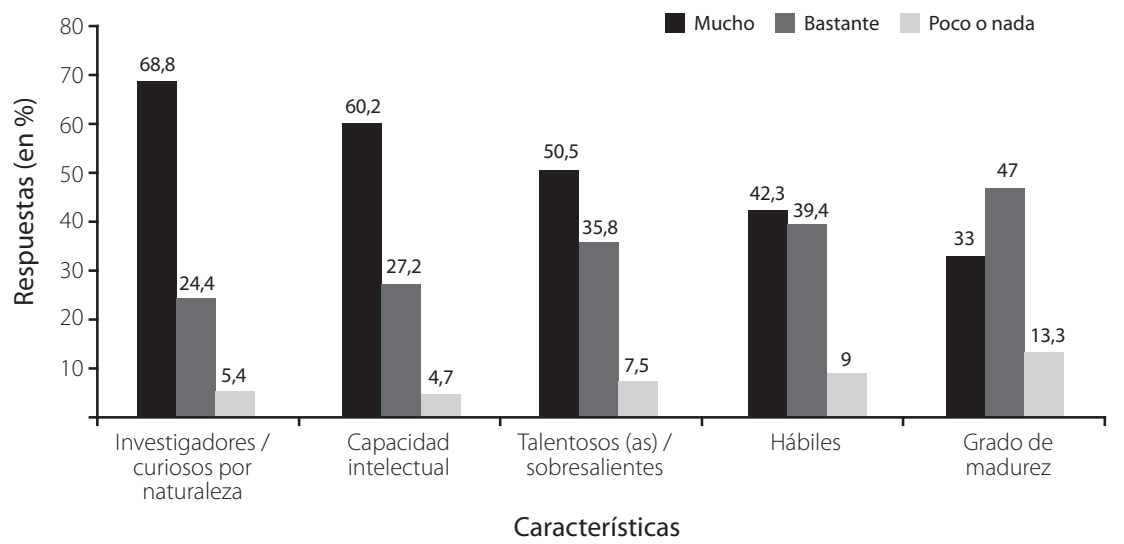

FIG. 1. Características que definen con mayor precisión a los niños (as) con superdotación según juicio de los docentes.

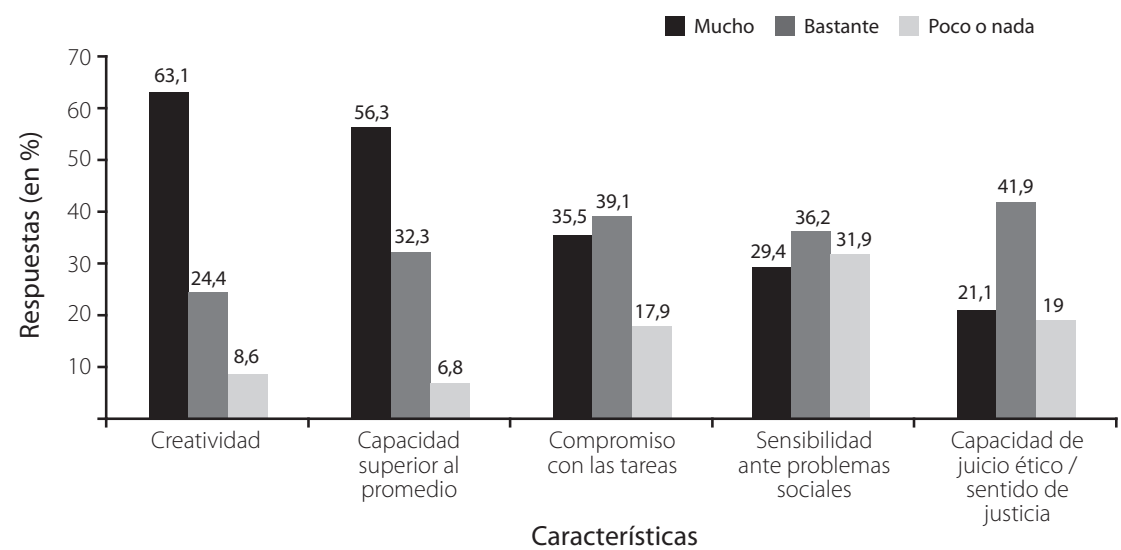

FIG. 2. Características que definen con mayor precisión a los niños (as) con superdotación según juicio de los expertos. 


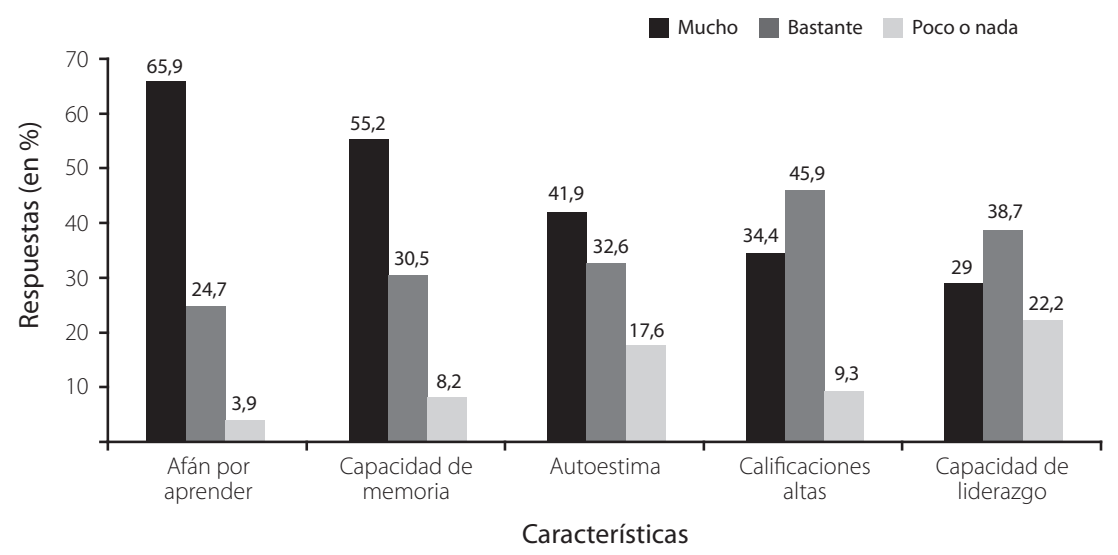

FIG. 3. Características que definen con mayor precisión a los niños (as) con superdotación según los argumentos teóricos.

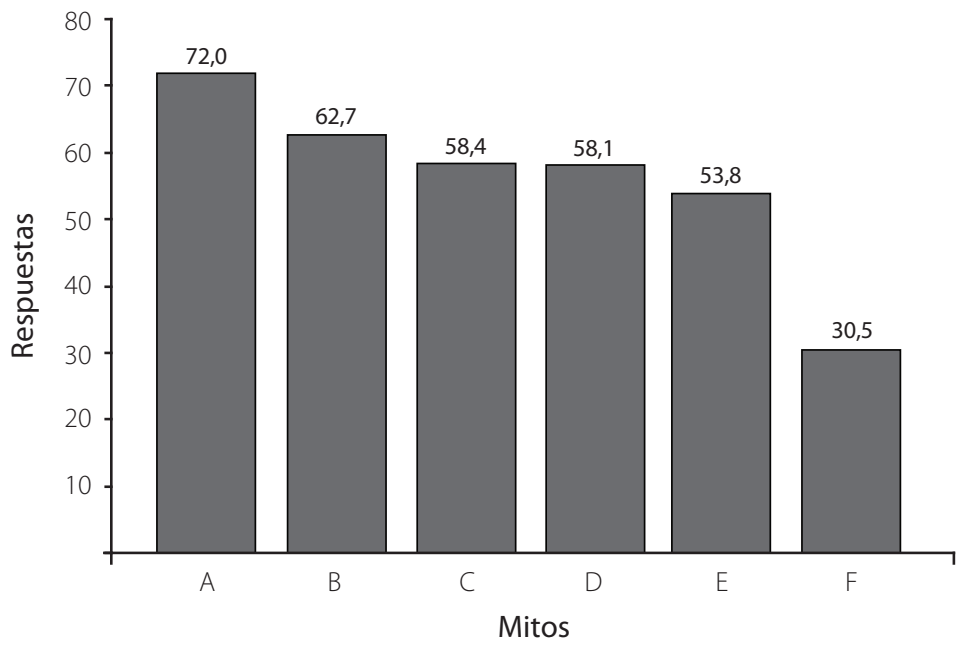

FIG. 4. Mitos o falsas creencias respecto a los niños (as) con superdotación según la opinión de los docentes. A. Son perfectos. B. No se pueden adaptar socialmente con niños de su edad. C. Son academicamente brillantes. D. Son superiores a sus iguales en todas las áreas académicas. E. Presentan un comportamiento estable a lo largo de su vida. F. El entorno y la familia influyen en el desarrollo de sus capacidades. 
capacidad de juicio ético, sentido de justicia y liderazgo también muestran coincidencia entre los entrevistados y los expertos.

Los docentes también expresaron opiniones que son consideradas mitos por los expertos, como que todos estos educandos son académicamente brillantes, que este alumnado es superior a sus pares en todas las áreas académicas, que presentan un comportamiento estable en las diferentes etapas del desarrollo, y que no pueden adaptarse socialmente a niños/as de su edad cronológica. Aunque un porcentaje menor a los de los mitos citados anteriormente, también se mencionó que el ambiente y la familia no afectan el desarrollo de las altas capacidades de los niños superdotados (Fig. 4).

Al cuestionar a los entrevistados sobre si hay diferencias entre los aspectos psicológico e intelectual de los niños, la mayoría opina que si hay diferencias (Fig. 5).

En cuanto a la actitud de los docentes frente a este tipo de estudiantes, estos mostraron gran apertura a brindarles una atención adecuada a las capacidades de este segmento de la población estudiantil, sin embargo reconocen que su formación profesional no les ha dado las herramientas necesarias y no se sienten bien preparados para brindar dicha atención. (Cuadro 3).

Aunado a lo señalado anteriormente, la mayoría de los docentes entrevistados manifiesta que el alumnado con superdotación presenta necesidades educativas especiales (Fig. 6), y que no se sienten capacitados para dar atención educativa adecuada a los aprendices con superdotación y que quizás estos deberían ser atendidos por docentes especializados (Fig. 7). Además consideran que sería necesario desarrollar programas educativos diferenciados para estos estudiantes (Fig. 8).

Por otra parte, los resultados de las encuentas muestran que proporciones importantes de los docentes desconocen los conceptos de enriquecimiento curricular,

CUADRO 3

Opinión de los docentes acerca de su relación con alumnos con superdotación

\begin{tabular}{lcccc}
\hline & $\begin{array}{c}\text { ¿Hay diferencias } \\
\text { importantes entre la edad } \\
\text { cronológica y la madurez } \\
\text { emocional de los niños con } \\
\text { superdotación? }\end{array}$ & $\begin{array}{c}\text { ¿Es conveniente la } \\
\text { con superdotación? }\end{array}$ & $\begin{array}{c}\text { iLos docentes tienen ¿Está usted capacitado para realizar } \\
\text { capacidad para dar } \\
\text { atención educativa } \\
\text { adecuada al alumno } \\
\text { lastervenciones educativas que } \\
\text { pueden requerir los (as) alumnos } \\
\text { con superdotación? }\end{array}$ \\
\hline Si & 65,9 & 16,1 & 20,4 \\
No & 24,4 & 17,2 & 79,9 & 65,6 \\
NS/NR & 9,7 & 19,0 & 3,9 & 14,0 \\
Total & 279 & 279 & 279 & 279 \\
\hline
\end{tabular}

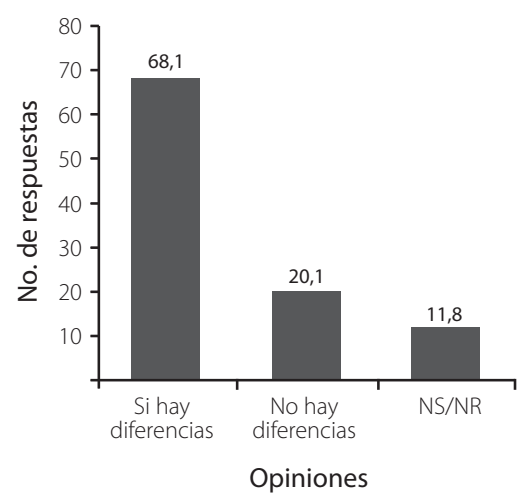

FIG. 5. Respuestas de los encuestados a la pregunta: ¿Existen diferencias importantes entre el desarrollo psicológico e intelectual de los niños con superdotación?

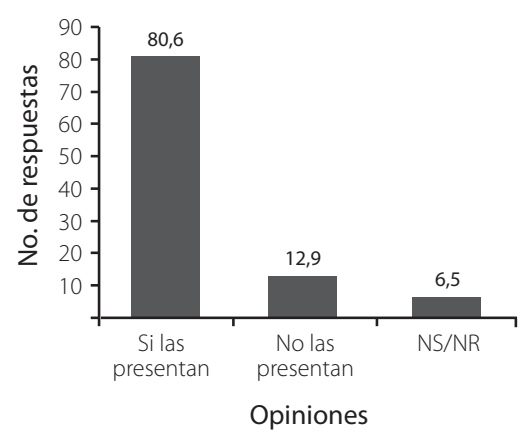

FIG. 6. Respuestas de los encuestados a la pregunta: ¿Presentan necesidades educativas especiales los niños con superdotación? 
aceleración, agrupamiento y adaptaciones curriculares (Fig. 9).

Finalmente, los entrevistados, en general no han recibido formación profesional ni capacitación en el tema de la superdotación (Fig. 10).

\section{DISCUSIÓN}

Los docentes consideran las altas calificaciones como un descriptor de la superdotación, lo cual no siempre es así, porque aunque los educandos con superdotación poseen el potencial para destacarse en cualquier ámbito del aprendizaje, no necesariamente suelen obtener altas cali- ficaciones, ni manifiestan sus capacidades, ya sea porque su mayor motivación esta dirigida hacia un campo muy específico o porque la escuela no es estimulante (Rezulli 1977, Alonso y Benito 2004 a, b, c).

Aunque su visión general del tema tiende a coincidir con la de los expertos contemporáneos, respecto a los descriptores o rasgos que definen la superdotación, aún creen en diversos mitos, como por ejemplo, que los individuos con superdotación "son todos académicamente brillantes" o "perfectos" (Corit 1990, Verhaären 1991, Colom 1998)

También consideran que la población educativa con superdotación posee necesidades educativas especiales

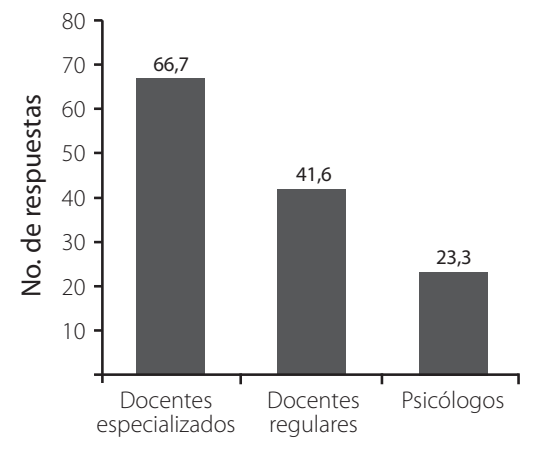

Responsables

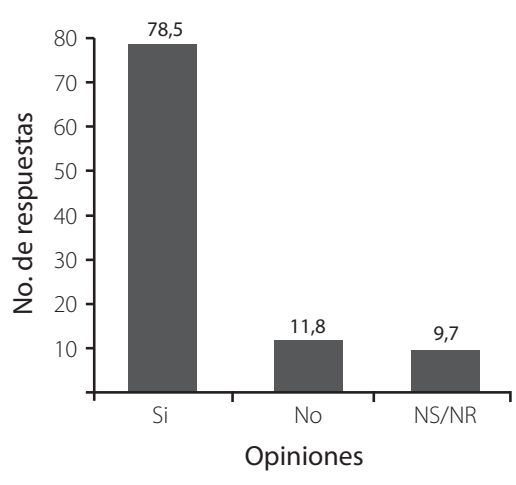

FIG. 8. Respuestas de los encuestados a la pregunta: ¿Deben desarrollarse respuestas educativas diferenciadas para atender a los niños con superdotación?

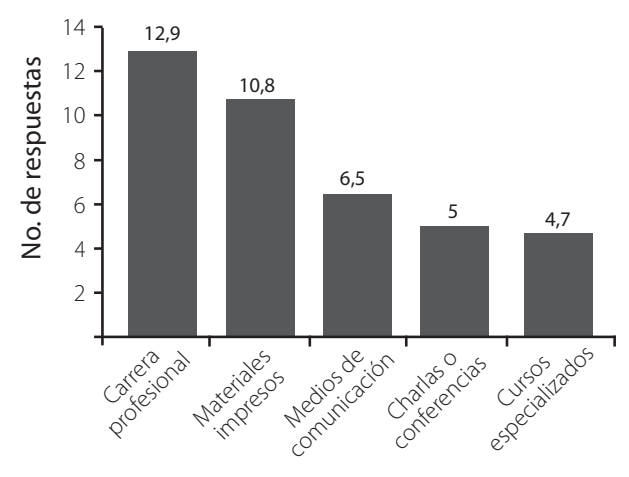

Fuente de capacitación

FIG. 10. Tipos de capacitación o formación profesional recibida.
FIG. 9. Respuestas de los encuestados a la pregunta: Defina los conceptos adaptación curricular, enriquecimiento curricular, aceleración y agrupamiento.

gunta: ¿Quienes deben atender las necesidades educativas de los niños con superdotación?

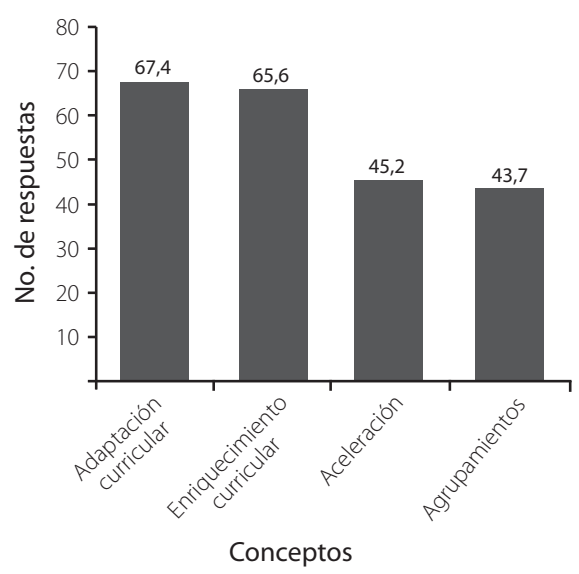


importantes que no están siendo satisfechas pedagógicamente, porque el personal docente no está capacitado para atenderlas adecuadamente. Sin embargo, están de acuerdo en la integración de la población con superdotación dentro del sistema educativo regular (Rezulli 1977, Corit 1990, Verhaären 1991, Colom 1998, Alonso y Benito 2004 a, b, c).

\section{AGRADECIMIENTOS}

Agradezco la colaboración del Señor Viceministro de Educación Pública, Wilfrido Blanco, a la Directora Nacional de Preescolar del MEP, Ana Isabel Cerdas, al personal docente de las escuelas: Juan Chávez en San Carlos y Cariblanco en Venecia, y a todo el personal escolar, madres y padres de familia, que colaboraron. Además, a los profesores Leda Morales, Siany Gamboa, Patricia Delgado, Olga Barahona, Xenia Vargas, Elmer Villalobos, Eliza Murillo, Elieth Varela y Lucrecia Hong, por su apoyo en la investigación.

\section{RESUMEN}

Pocos países tienen el personal e instalaciones adecuadas para atender educandos con superdotación. Se encuestó a una muestra de 279 docentes (preescolar y primaria) en las provincias de San José, Limón y Alajuela, Costa Rica sobre sus conocimientos del tema, características de educandos superdotados y su propia capacidad para atenderlos. Aunque su visión general del tema tiende a coincider con la de los expertos sobre los rasgos de la superdotación, aun creen en diversos mitos. Opinan que el personal docente no está capacitado para atenderlo adecuadamente y están de acuerdo en integrar a esta población dentro del sistema educativo regular.

\section{PALABRAS CLAVE}

Superdotación, talentos, educadores, necesidades educativas especiales, investigación, agrupación, aceleración, adaptación curricular, enriquecimiento curricular, integración.

\section{REFERENCIAS}

Alonso, J. \& Y. Benito. 2004. Necesidades educativas y sociales de los alumnos superdotados. Bonum, Buenos Aires, Argentina.

Benito, Y. \& J. Alonso. 2004a. Sobredotación intelectual I: Definición e identificación. UTPL, Loja, Ecuador.

Benito, Y. \& J. Alonso. 2004b. Sobredotación intelectual II: Superdotados, talentos, creativos y desarrollo emocional. UTPL, Loja, Ecuador.

Benito, Y. \& J. Alonso. 2004c. Sobredotación intelectual III: Intervención familiar y académica. UTPL, Loja, Ecuador.

Colom, R. 1998. Psicología de las diferencias individuales. Pirámide, Madrid, España.

Corit, A. 1990. Los niños superdotados. Herder, Barcelona, España.

Morales, K. 2007. Identificación temprana de la niñez con superdotación en Costa Rica. Ideacción 27:1-11.

Renzulli, J. 1977. The enrichment triad model: a guide for developing defensible programs for the gifted and talented. Mansfield Center, CT. Creative Learning, Connecticut, EEUU.

Verhaären, P. 1991. Educación de alumnos superdotados. Ministerio de Educación y Ciencias, Madrid, España.

Vygotsky, L. 1987. Historia del desarrollo de las funciones psíquicas superiores. Científico Técnica, La Habana, Cuba. 


\section{APÉNDICE 1}

Frecuencias simples: Población muestral

Cuadro A-1

Tipo de escuela: rural o urbana

\begin{tabular}{lc}
\hline Tipo de escuela & Entrevistados (\%) \\
\hline Urbana & 84,6 \\
Rural & 15,4 \\
Total & $\mathbf{2 7 9}$ \\
\hline
\end{tabular}

Cuadro A-2

Ubicación de la escuela

\begin{tabular}{lc}
\hline Ubicación & Entrevistados (\%) \\
\hline Dentro del GAM & 62,7 \\
Fuera del GAM & 37,3 \\
Total & 279 \\
\hline
\end{tabular}

GAM: Léase Gran Área Metropolitana

Cuadro A-3

Escuelas por provincia

\begin{tabular}{lc}
\hline Provincia & Entrevistados (\%) \\
\hline San José & 56,6 \\
Alajuela & 14,3 \\
Limón & 29,0 \\
Total & 279 \\
\hline
\end{tabular}




\section{APÉNDICE 2}

Muestra del instrumento aplicado en la entrevista a los docentes de escuelas urbanas

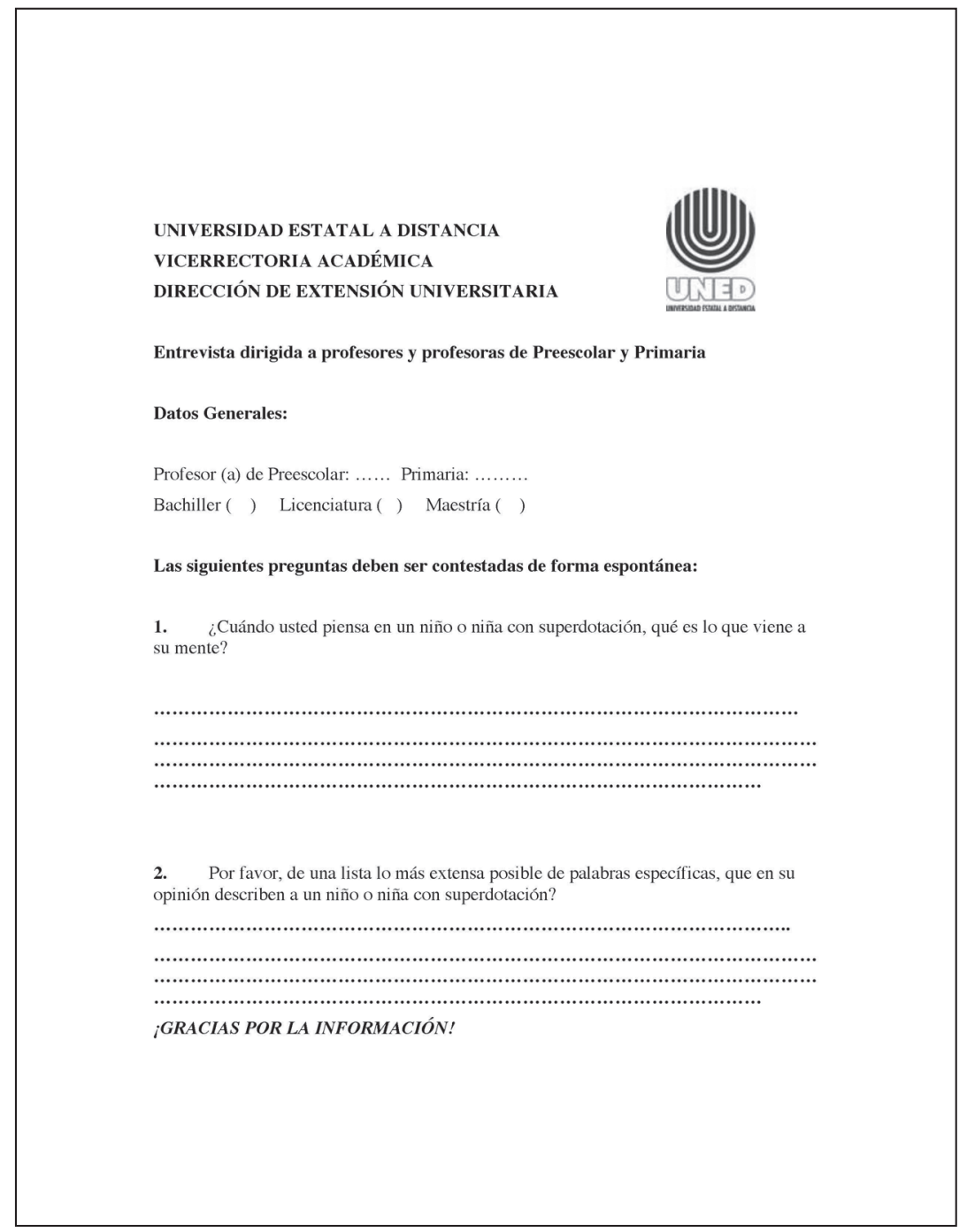




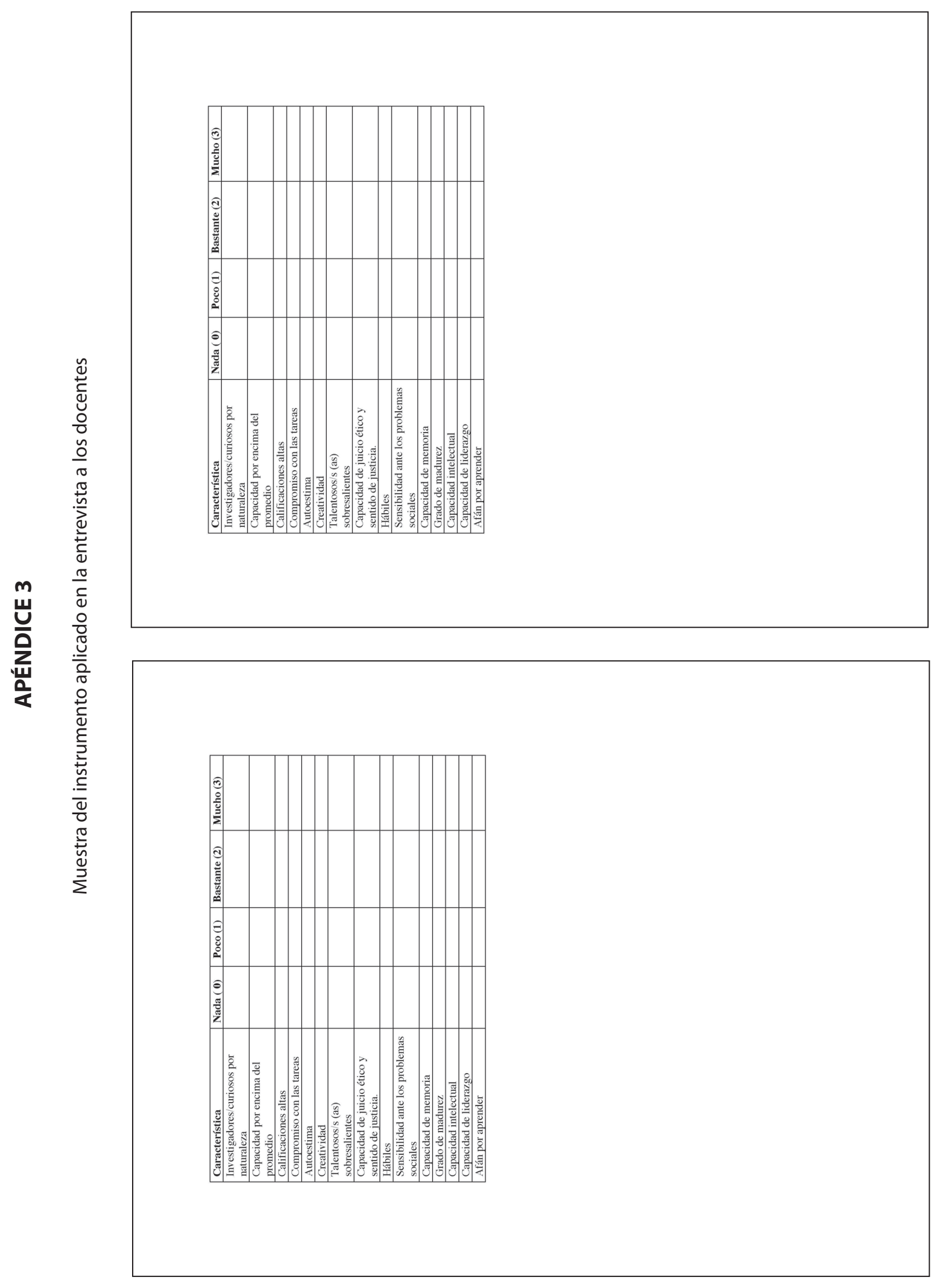



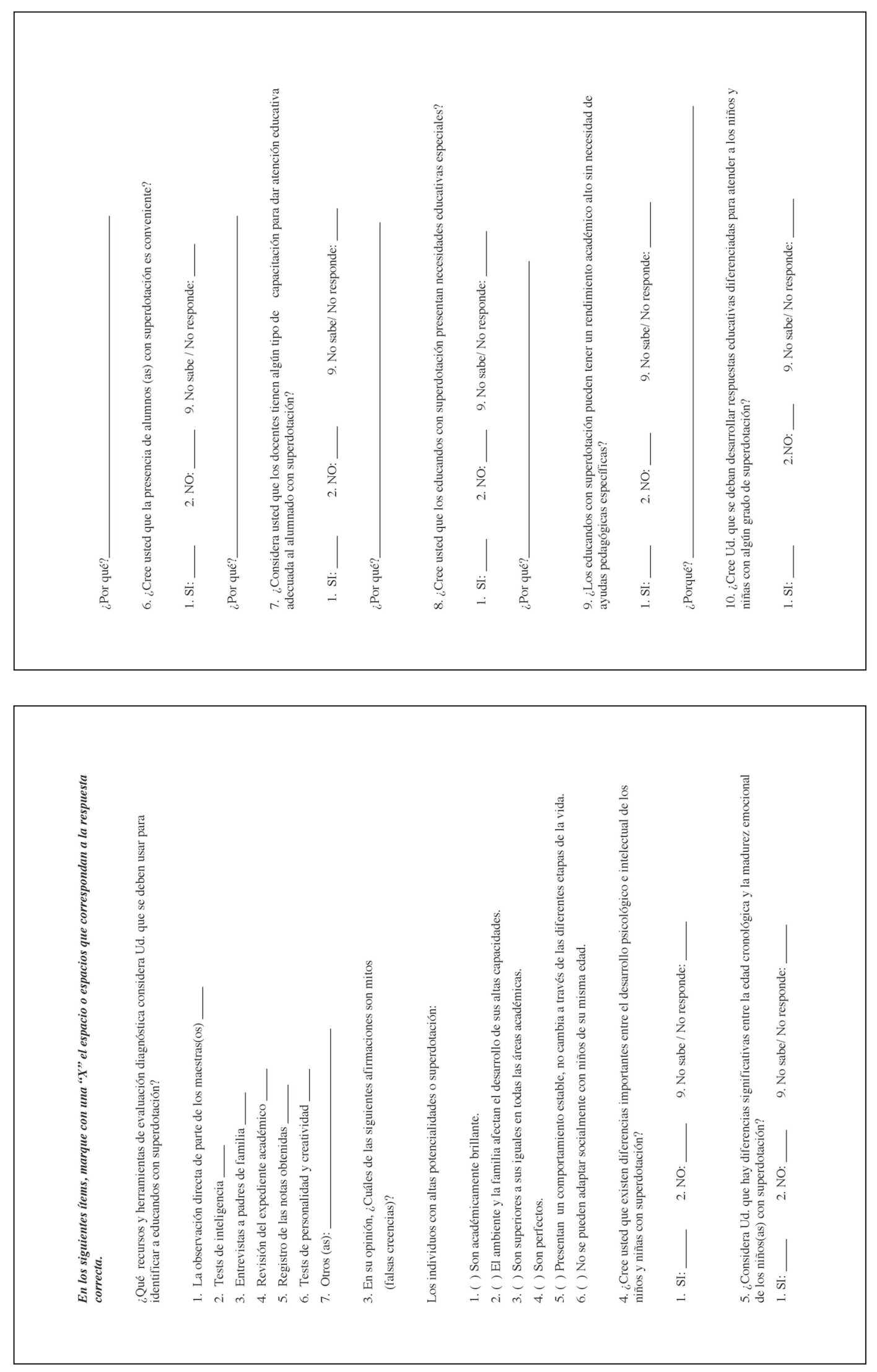

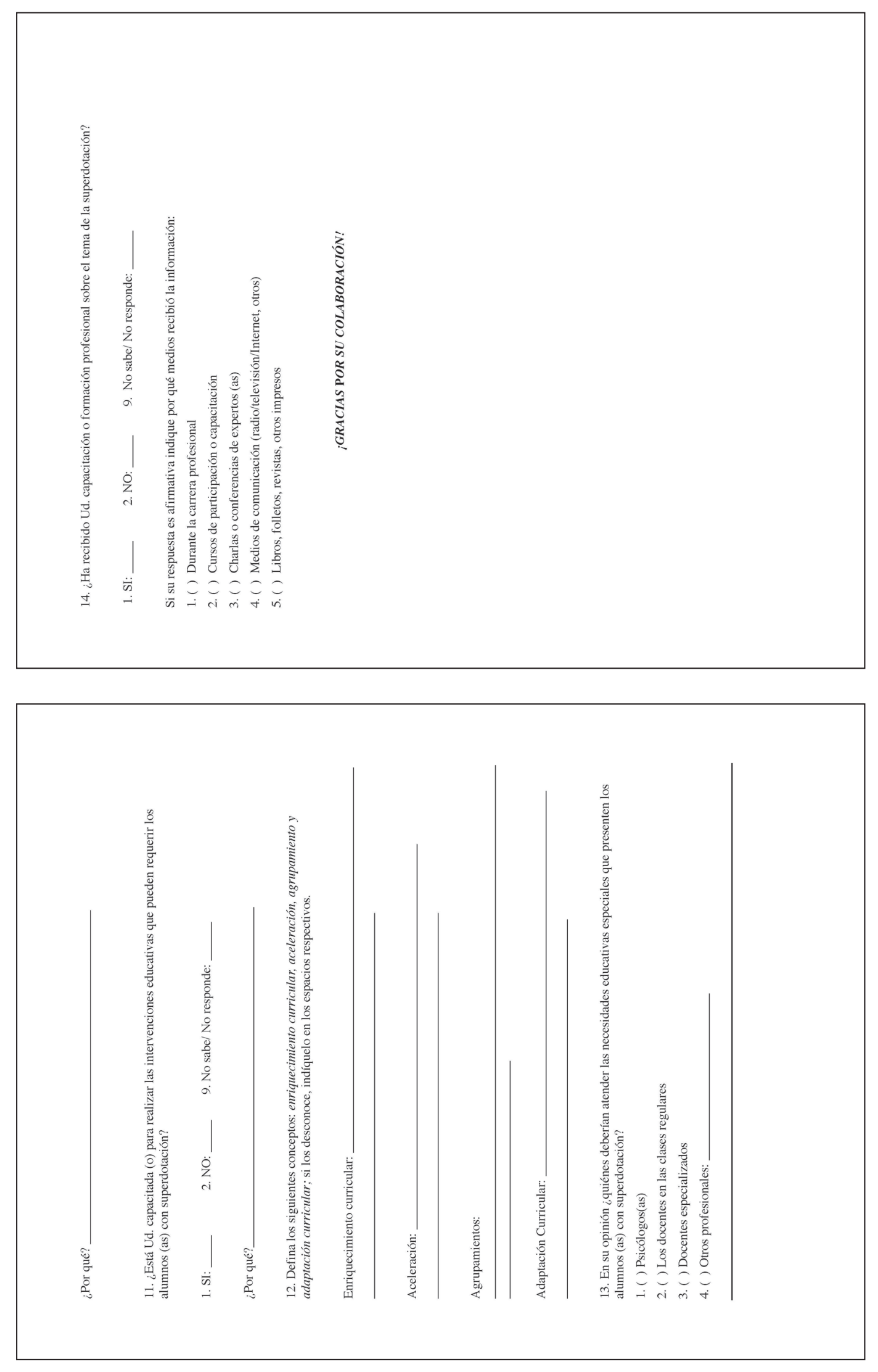